\title{
INVESTIGATING THE EFFECT OF AERATION ON THE FLOW CHARACTERISTICS AROUND UNDER PRESSURE TUNNEL AERATOR USING OPENFOAM OPEN SOURCE SOFTWARE
}

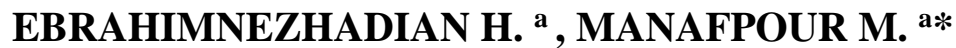 \\ ${ }^{a}$ Urmia University, Faculty of Engineering, Department of Civil Engineering, Iran, \\ e-mails: h.ebrahimnezhadian@urmia.ac.ir,*m.manafpour@urmia.ac.ir
}

Received: 22.01.2019 / Accepted: 30.03.2019 / Revised: 24.04.2019 / Available online: 31.05.2019

DOI: 10.2478/jaes-2019-0006

KEY WORDS: Aerator, Pressurized tunnel, RNG K- $\varepsilon$ Turbulence Model, OpenFOAM, Cavity length, Aeration Coefficient ( $\beta$ ).

\begin{abstract}
:
The flow around the ramp embedded in a pressurized tunnel is divided into the various zones immediately downstream of the ramp, including the cavity and the main zone of flow above the shear layer. The aeration coefficient of the flow from the lower surface (inside the cavity)( $\beta_{\text {lower }}$ ) is a function of non-dimensional numbers which aerator geometry parameters such as cavity length to ramp height $\mathrm{L}_{\mathrm{c}} / \mathrm{t}_{\mathrm{r}}$ is considered as one of the most important parameters. Therefore, in the present study, OpenFOAM software and RNG k$\varepsilon$ turbulence model were used to simulate the flow to study the aeration effect on flow characteristics, so the range of aeration coefficient as $0 \%<\beta<10 \%$ for four ramps with different $t_{r} / d$ ratios is Applied, then by increasing the aeration coefficient in the range of $0 \%<\beta<16 \%$, The dependency range of relative Cavity length $L_{c} / t_{r}$ to $(\beta)$ was evaluated. In order to verify performance of the numerical model, experimental results of Manafpour test were used. The results of the research indicate that in the aeration of flow with aerator ramp, the height of ramp has more influence relative to ramp angle. Moreover the main Effectiveness of the aeration coefficient on the cavity length was limited to air percent less than $10 \%$.
\end{abstract}

\section{INTRODUCTION}

Aeration is known as the most efficient and economical method for prevention of cavitation in high-speed flows over chute spillways (Pinto, N.L., 1984 \& wood, I.R., 1991). With 8\% air near the concrete surface damage of cavitation attack is completely prevented (Peterka, A.J., 1953 \& Zhang, J.M., 1991). Surface aeration takes place in spillways but in this way usually not enough air is introduced near the concrete surface (May, R.W.P., 1987). Therefore, with regard to the danger of cavitation attack, forced aeration of flow is recommended (Falvey, h.t., 1990 \& Pinto, N.L., 1991). Aerators, which locally create an air cavity at the lower boundary of the flow, have been found to be an effective and cheap way of promoting air entrainment into the flow. Aerators cause the flow to separate from the surface of the spillway and form a nappe (Fig. 1).

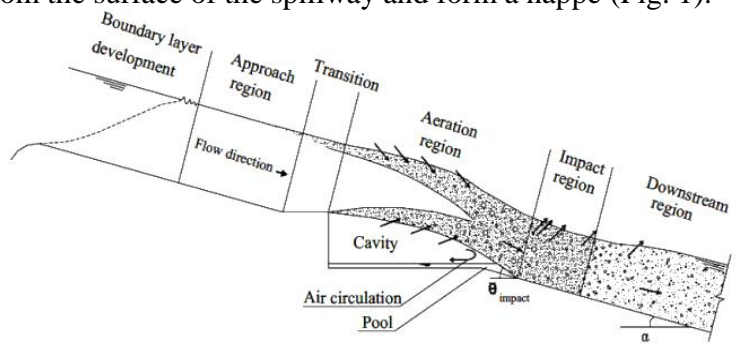

Figure 1. Flow region over typical aerator
Flow behavior on aerator ramps in Fig. 1 shows the complex interaction between flow turbulent structures, the phenomenon of cavitation, the behavior of the jet in the atmosphere, the air entering the jet, as well as the propagation of bubbles in the downstream of ramps. Air will then be entrained along the lower surface as well as along the upper surface of the nappe (Chanson, H., 1991). The entrainment on the lower surface introduces air bubbles near the bed of the spillway for some distance downstream (Chanson, H., 1989 \& Zarrati, A.R., \& Hardwick, J.D., 1995).

In under pressure flow upon ramp aerator embedded in the tunnel floor, immediately downstream of the ramp such as Figure 2, the flow is two-phase and disturbed and there is no surface aeration and divided into the various zones immediately downstream of the ramp, including the cavity zone and the main zone of flow above the shear layer.

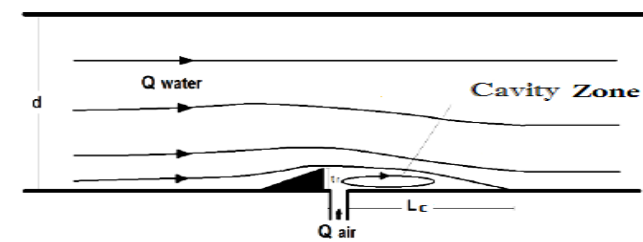

Figure 2. Flow pattern upon under Pressure tunnel ramp

\footnotetext{
* Corresponding author: Hamzeh Ebrahimnezhadian, e-mail: m.manafpour@urmia.ac.ir
} 
As flow separates from the trailing edge of the ramp, the lower layers accelerate and small Intense eddies form on the lower surface of the nappe which roughens the air-water interface Fig. 2. As turbulence overcomes surface tension, this air will be entrained into the flow. On the other hand, the pressure distribution in the nappe rapidly adjusts itself to near atmospheric conditions and the slip velocity of air bubbles falls and air bubbles are diffused by turbulence deeper into the core of the nappe. Further downstream, more and more air will be entrained into the flow (Zarrati, A.R., 1993). Turbulence plays an important rule here, and higher turbulence levels cause more air entrainment (Ervine, D.A., \& Khan, A.R 1991, May, R.W.P., et al 1991).

The introduction of forced air, especially from the bottom of the jet, will increase the concentration of air near the surface of the concrete. Aeration in spillways and under pressure tunnels is usually carried out by aeration systems and using ramp, groov and steps. The most common type of aeration can be seen in Fig. 3. Bringing the air to the bottom of the jet, as shown in Figure 3 is carried out by a duct from the floor. In this way, the flow is completely aerated and despite this air near the floor, the damage caused by cavitation is prevented.
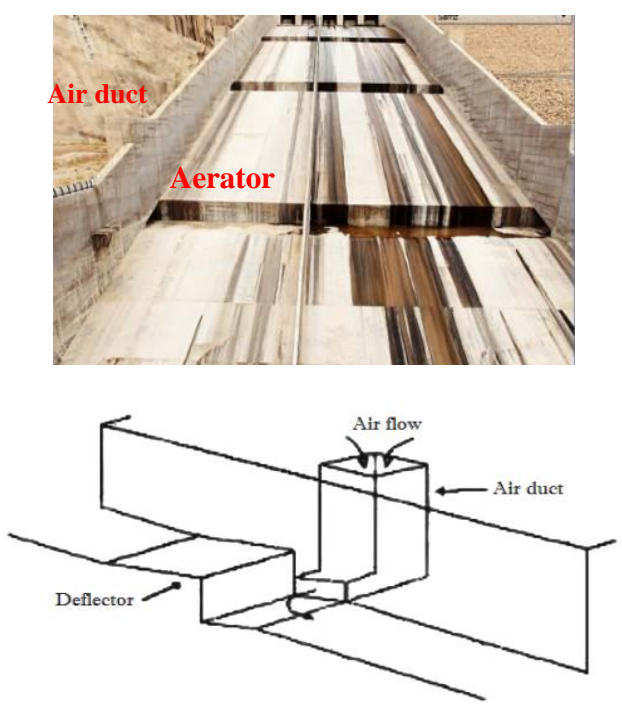

Figure 3. Fluid aeration systems (Chanson, H., 1994)

Proper recognition of the two-phase flow pattern in under pressure tunnel spillways with and without aeration system is among the topics studied by a number of researchers, and because of the complexity of two-phase flows, there is still a need for more laboratory and numerically studies in this field. Part of the studies on the flow around the ramp aerator in pressure tunnels which are often also provided in laboratory form is expressed in next section. Many research works has been done to find the relationship between the inflows of air through aerators. According to Pinto's 1984 research, relative air discharge $(\beta)$, which is defined as the ratio of air to water discharge, is a function of the cavity length, the Froude number and cavity subpressure. In 1990, Falvey presented a mathematical model based on Galzoo's work in 1984 (Glazov, A.T., 1984). This model computed the cavity length as well as the airflow and cavity subpressure. Based on this model, Cavity length directly affected the airflow.
Zheng et. al studied and compared VOF and Mixture methods during a series of experimental and numerical studies with three-dimensional simulation of aerated flow downstream of ramp aerator in a under pressure tunnel. Comparing the numerical and experimental results indicates that both methods accurately calculate the free water surface and cavity length. Air concentration inside the water and the average values of pressure downstream of aerator from Mixture model have less error than the experimental results (Zhang, JM., Chen, JG., \& $\mathrm{Xu}, \mathrm{WL}, 2011)$.

$\mathrm{Wu}$ and $\mathrm{Ma}$ examined the effects of flow regime downstream of aerator on entering the air into the flow and preventing damage of cavitation. The results of the experiments showed that the conversion of flow regimes downstream of aerator to each other depends on aerodynamic parameters such as ramp angle, ramp height and slope of tunnel floor (Wu, J., Ma, F., \& Dai, H.C., 2011).

Ruan et. al compared laboratory performance with two types of aerator in two different designs, According to the parameters of cavity length, the pressure field downstream of aerator, relative air discharge $(\beta)$ and air concentration within the water flow. As a result of these experiments, it was found that for tunnel spillways, the shape and size of aerator require special design and tunnel spillways can be protected from cavitation by applying a plan of aerator that increases the cavity zone length, the inflow of air and the air concentration near the floor (Ruan, S.P., Wu, J.H., \& Wu, W.W., 2007)

Kavianpour et. al carried out laboratory studies on measuring the pressure fluctuations in downstream of the aerator located in a circular tunnel and studied aerator performance with different geometries. According to the results of the experiments, it was found that the use of aerator with small heights for air supply in tunnel duct is more suitable than aerator with high heights from a hydrodynamic point of view (Kavianpour, M., Toloui, A., \& al-Mu'zsoumi, AS., 2002)

Bhosekar et. al studied the effect of geometric and hydraulic parameters on the pressure, cavity length and relative air discharge $(\beta)$ in flow around ramp embedded at the end of the tunnel. As a result of this research it was found that by increasing the relative cross-section of the inflow of air, which leads to an increase in the amount of air entering the flow. The cavity length downstream of the ramp and the aeration coefficient of the flow increases. The average cavity pressure also increases significantly with increasing inflow of air into the flow (Bhosekar, V.V., Jothiprakash, V.Y., \& Deolaikar, P.B., 2012).

Narayanan et. al carried out Experiments to study the effect of air injection on the wall pressure in the near field of deflectors placed in a duct. Various quantities of air have been injected just downstream of the ramps to form stationary air cavities. The variation of cavity length has been studied as function of the ratio of the volume of air flow to the water discharge. The wall pressure field in terms of the mean and fluctuating parts is presented. This study shows how air injection affects the wall pressure field from that without air injection. Information concerning wall pressure is expected to be useful in the design of deflectors in tunnels and spillways (Narayanan, R., Manafpour, M., \& Kavianpour, R., 2000). 
Computational Fluid Dynamics (CFD) has emerged as an important alternative in multiphase flow modelling. Both methods are undoubtedly complementary to each other. With CFD, it is possible to obtain, in detail, air-water flow fields of the aerated flow so as to understand the effects of governing parameters necessary for a project in question. Part of the studies on the flow around the ramp aerator in free surface flow which are often also provided in laboratory form is expressed in next section.

The VOF Model is sometimes used to simulate aerator flows (Zhang, JM, Chen JG, Xu WL., 2011; Deng, J., Xu, W. L., Lei, J., and Diao, M. J., 2005; Jothiprakash, V. Y., Bhosekar, V. V., and Deolaikar, P. B., 2015; Liu, T., and Yang, J., 2014); Kökpınar, M. A., and Göğüş, M., 2002; some researchers employ the Mixture Model to study an aerator flow and found that the model is more suitable for simulating aerator flows and especially in high air-concentration regions (Rahimzadeh,H., Maghsoodi, R., Sarkardeh, H., and Tavakkol, S., 2012; Aydin, M. C. and Ozturk, M., 2009).

Zhang et al. carried out three-dimensional (3D) modelling with the model. He focused on evaluations of such parameters as the diameter of air bubble, wall function, and interphase exchange models (Zhang, J. M., Chen, J. G., and Xu, W. L., 2011). Zhang et al. performed two-dimensional (2D) simulations using the model, in which the turbulence dispersion force was included in the momentum equations. They concluded that the inclusion of the turbulence dispersion force gave better results of air concentration in the flow, which agreed well with the experimental data (Zhang, X. D., 2004; Zhang, H. W., Liu, Z. P., Zhang, D., and Wu,Y. H., 2008).

In this study, in order to investigate the effect of dimensionless geometry parameters on aeration coefficient and aeration effect on flow characteristics in various relative air discharge $0 \%<\beta<10 \%$, for four ramps A, B, C and D with different ratios $\left(\mathrm{t}_{\mathrm{r}} / \mathrm{d}\right)$ is Applied and then by increasing the relative air discharge coefficient $(\beta)$ in the range of $0 \%<\beta<16 \%$, The dependency range of relative Cavity length $\left(\mathrm{Lc} / \mathrm{tr}_{\mathrm{r}}\right)$ to $(\beta)$ was evaluated.

\section{MATERIAL AND METHODS}

\subsection{Experimental setup}

The details of experimental arrangement have been described in Fig. 4. The experimental model consist of a horizontal pressurized duct with a square cross section that ramps of Perspex of triangular cross section were glued to the bottom of duct. Four ramps were used for the study. Two heights of $\mathrm{t}_{\mathrm{r}} / \mathrm{d}=0.1$ and 0.2 were used. $\mathrm{tr}$ is the height of the ramp and $\mathrm{d}$ is the height of the duct. For each value of $t_{r} / d$ test, two slopes of $5^{\circ}$ and $10^{\circ}$ were used. Water supply to the duct housing the ramps was from a constant head tank located on the roof of the laboratory. A $0.1 \mathrm{~m}$ wide and height duct was used with a tank upstream to achieve the desired flow velocities. The modeled aerator consisted of a ramp. Dimensions of the aerator are given in Table 1. The aerator was installed $1 \mathrm{~m}$ downstream of the channel entrance to allow the turbulent boundary layer to develop completely. To measure flow velocity a Pitot tube was employed. Air was introduced through nine holes of diameter $10 \mathrm{~mm}$ placed at regular intervals immediately downstream of the ramps (Manafpour, M., 2004).

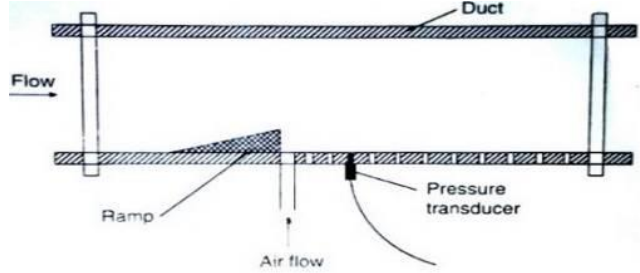

Figure 4. Experimental apparatus

Table 1. Characteristic of Studied Ramps

\begin{tabular}{|c|c|c|c|c|}
\hline Ramp & $\begin{array}{c}\text { Ramp height } \\
\mathrm{t}_{\mathrm{r}}(\mathrm{mm})\end{array}$ & $\begin{array}{c}\text { Ramp Length } \\
\mathrm{L}_{\mathrm{r}}(\mathrm{mm})\end{array}$ & $\begin{array}{c}\text { Ramp } \\
\text { Angle }(\theta)\end{array}$ & $\mathrm{t}_{\mathrm{r}} / \mathrm{d}$ \\
\hline $\mathrm{A}$ & 10 & 113.4 & 5 & 0.1 \\
$\mathrm{~B}$ & 10 & 56.7 & 10 & 0.1 \\
$\mathrm{C}$ & 20 & 226.8 & 5 & 0.2 \\
$\mathrm{D}$ & 20 & 113.4 & 10 & 0.2 \\
\hline
\end{tabular}

\subsection{Numerical Model}

In the present study, OpenFOAM open source software was used to simulate the flow around the aerator ramp embedded in a under pressure duct.

2.2.1 OpenFOAM: The widely known CFD-toolbox "OpenFOAM" (Open Field The official version of OpenFOAM is distributed under the GNU license by ESI/OpenCFD (www.openfoam.org). For post-processing results of OpenFOAM simulations, the open source software ParaView can be used. With ParaView, even domain decomposed cases (that were calculated in parallel on several CPUs and are stored in separate directories for each domain), can be post-processed without reconstructing the case. In contrary to most CFD programmes, OpenFOAM is not delivered with a graphical user interface for performing the pre- and post-processing of the simulations (Zhang JM, Chen JG, Xu WL., 2011).

The most important difference between open source software OpenFOAM and other computational fluid dynamics commercial software, including Fluent and CFX, That is, in OpenFOAM software to create a model in each subcategory, the indices needed to carry out the software project must first be defined and then use an exclusive solver, while in other software mentioned, only the indices needed to create the model are included in the software and immediately the problem is solved. Therefore, one of the difficulties of open source software OpenFOAM is the choice of proportional solver. The flow around the under pressure tunnel ramp aerator have twophase nature. Multiphase flow modelling is performed using the three views, 1- Volume of Fluid 2- Eulerian-Lagrangian 3Eulerian- Eulerian, which the VOF method is used to solve multiphase systems involving two or more immiscible fluids with emphasis on capturing the interface and can use for problem such as dam break and Jet breakup, in the EulerianLagrangian method, continuous-phase from the Eulerian Approach and the dispersed phase (motion and particle tracing) from the Lagrangian Approach is modelled. This method is suitable for two-phase flows with less than $10 \%$ Volumetric of dispersed phase and in the Eulerian-Eulerian Approaches, both continuous and dispersed phases are considered as continuous phases, this method is used for industrial systems with billions 
of solid particles, with a dispersed phase content of more than $10 \%$.

In OpenFOAM software, to analyze multiphase flow problems, various solvers are foreseen. Choose a suitable solver is the most important part of the simulation in OpenFOAM open source software. Table 2 shows a number of multiphase solvers in the OpenFOAM.

Table 2. Multiphase Solver in OpenFOAM

\begin{tabular}{|cc|}
\hline Multiphase solvers & Description \\
\hline interFoam & $\begin{array}{c}\text { solver for two incompressible fluids } \\
\text { capturing the interface using a VOF } \\
\text { method }\end{array}$ \\
bubbleFoam & $\begin{array}{c}\text { solver for 2 incompressible fluids to } \\
\text { compute dispersed gas-liquid and } \\
\text { liquid-liquid flows based on the Euler- } \\
\text { Euler two-fluid methodology } \\
\text { solver for 2 incompressible fluid } \\
\text { twoPhaseEulerFoa } \\
\mathrm{m}\end{array}$ \\
$\begin{array}{c}\text { phases with one phase dispersed based } \\
\text { on the Euler-Euler two-fluid } \\
\text { methodology }\end{array}$ \\
\hline
\end{tabular}

In this study, due to the two-phase nature of the flow and the importance of mixing the two phases in each other, the Eulerian- Eulerian approach and also a solver that have the basis of the twoPhaseEulerFoam solver is used and the necessary development in the solver to increase efficiency in the discussion of the two-phase mixing simulations has been done.

\subsection{Geometry, Meshing and Boundary Condition}

In order to construct the geometry of the numerical model, due to the various configurations in the present study, including the angles and height of the ramps, a code was written in the FORTRAN software. By applying the input data such as the ramp angle and height, the distance to the ramp entrance and the distance from the end of the ramp, the information necessary for constructing geometry from the FORTRAN code was extracted and transferred to the BlockMesh environment inside the OpenFOAM software. Regarding the dimensions of the study area and air bubble diameter, the geometry grid of the numerical model with dimensions of $2 \mathrm{~mm}$ was prepared. The meshing of the numerical model is visible in Fig. 5. The sensitivity analyze of the numerical model was measured relative to the mesh size, and it was found that using a smaller cell size did not affect the accuracy of the calculations.

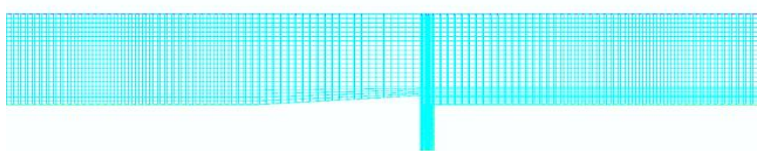

Figure 5. Numerical Model Meshing

The boundary conditions in the present study include the following; 1-water inlet: mass flow rate 2- air inlet: mass flow rate 3- outlet: pressure outlet and for all duct wall such as floor, ceilings and ramp, a wall boundary condition were used.

\section{RESULT AND DISSCUSSION}

In order to evaluate the performance of a numerical model in the simulation of two-phase flow around aerator ramp embedded in under pressure duct bed for 4 types of ramps that are presented in Table 1 numerical and experimental results for number of parameters such as the cavity length immediately downstream ramp, the average flow velocity profiles and the changes in the pressure coefficients $\left(\mathrm{C}_{\mathrm{P}}\right)$ were compared. In the next step the flow near the aerator ramp in the various forced relative air discharge $0 \%<\beta<10 \%$ and a number of ramps as Table 1 was developed and simulated to determine the effect of different forced relative air discharge $(\beta)$ on the cavity lengths for different angles and $t_{r} / d$ ratios and finally to determine the Effectiveness range of relative air discharge coefficient $(\beta)$ on relative cavity lengths $\left(\mathrm{L}_{\mathrm{c}} / \mathrm{t}_{\mathrm{r}}\right)$, the range of relative air discharge $0 \%<\beta<16 \%$ was investigated.

\subsection{Verification of Numerical Model Results}

3.1.1 The Cavity Length ( $\mathbf{L}_{\mathbf{c}}$ ): After the passing flow through the aerator ramp, in addition to the main zone, the cavity zone is formed that this two regions are separated from each other by the shear layer between them as shown in Fig. 6 . In Figure 7 the comparison between the relative cavity lengths calculated by the numerical model Using the two-equation turbulence model RNG $K$ - $\varepsilon$ and experimental results for cavity formed immediately downstream of four different ramps in the various relative air discharge $(\beta)$ is showed in which $\mathrm{L}_{c}$ and $\mathrm{t}_{\mathrm{r}}$ are the length of the cavity zone and ramp height Respectively. According to Figure 7 the two-dimensional numerical model in all ramps estimates the cavity length less than the experimental model. The correlation coefficient between the relative cavity length of the numerical and experimental models for forced relative air discharge $2 \%, 4 \%, 6 \%$ and $8 \%$ was $0.9729,0.9371$, 0.946 and 0.966 respectively, which suggests an acceptable simulation of the flow by a numerical model. Results for $2 \%$ and $8 \%$ relative air discharge are presented.

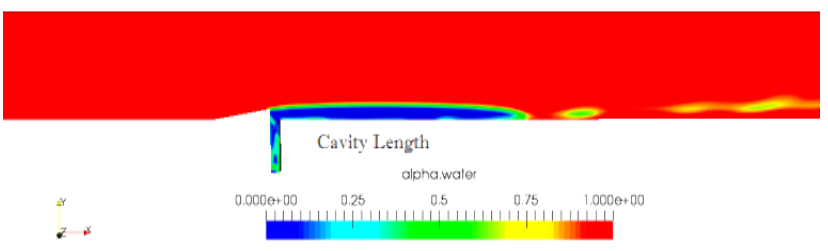

Figure 6. Cavity formed in the under pressure duct due to forced air injection.
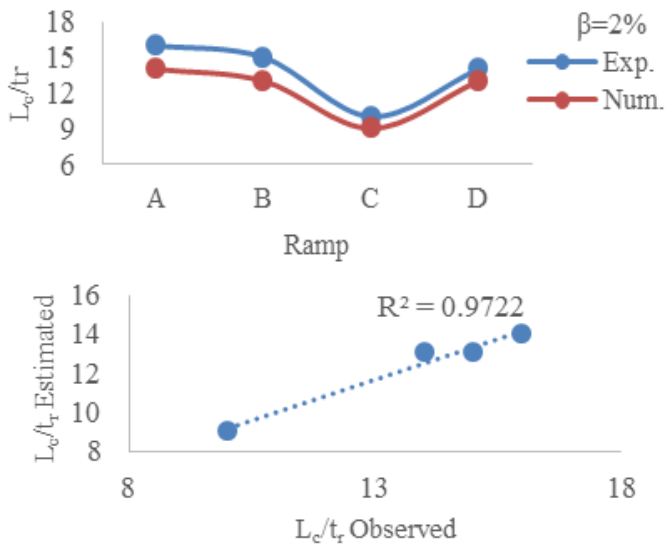

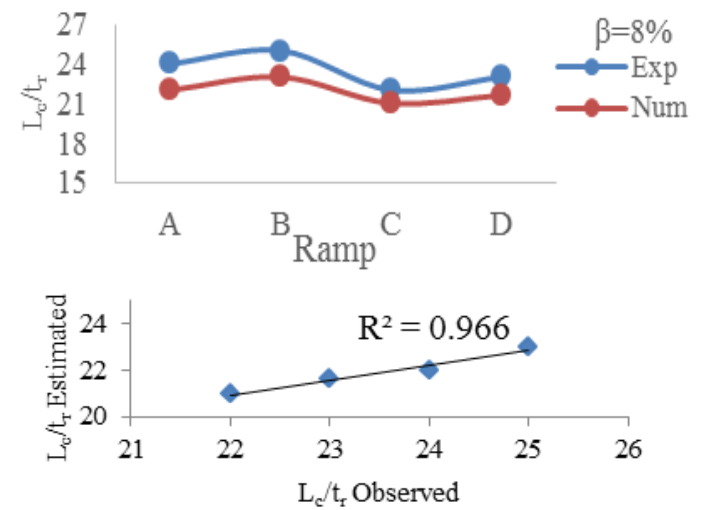

Figure 7. Comparison of the cavity length generated by numerical model and the experimental results and the correlation between the results

3.1.2 Flow Velocity: The comparison of average velocity distribution profiles between numerical and experimental results for ramp $\mathrm{D}\left(\mathrm{t}_{\mathrm{r}} / \mathrm{d}=0.2, \theta=10^{\circ}, \beta=2 \%\right)$ is displayed in Figure 8 where $\mathrm{Z}$ is the distance from the end of the ramp and $\mathrm{U}$ is the average velocity of the flow that equal to $4.1 \mathrm{~m} / \mathrm{s}$. The adaptation of numerical and experimental results suggests the proper accuracy of the numerical model in simulating the flow velocity field near the aerator ramp. According to Figure 8, the velocity in the direction of flow at the end of the ramp due to the Existence of ramp and the decrease of the duct cross section reaches its maximum value.
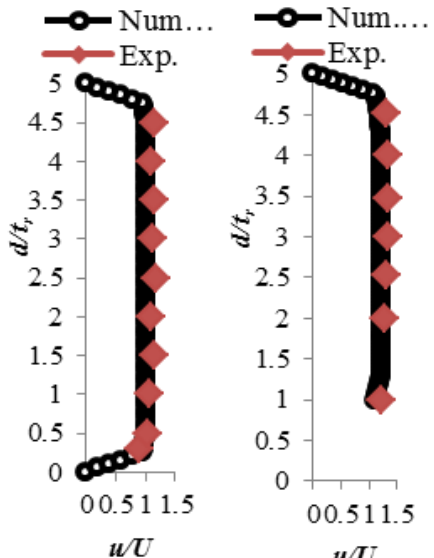

$\boldsymbol{w}$

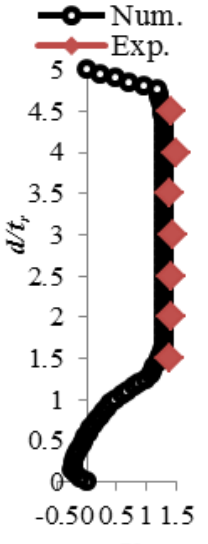

$u U$

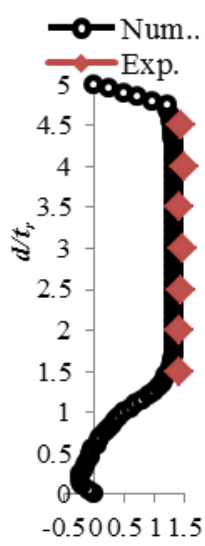

$u U$

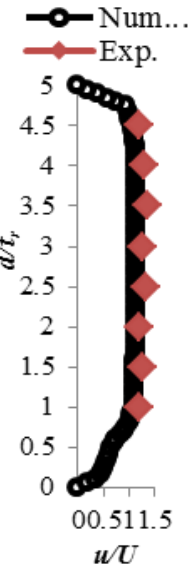

Figure 8. Flow velocity Profiles for $\operatorname{ramp} \mathrm{D}\left(\mathrm{t}_{\mathrm{r}} / \mathrm{d}=0.2, \theta=10^{\circ}\right)$, in section $\left(Z / t_{r}: a=-28, b=-0.2, c=2.1, d=6.7, e=15.7\right)$
3.1.3 Pressure Coefficient: The dimensionless parameter of the pressure coefficients $\left(\mathrm{C}_{\mathrm{P}}\right)$ is defined as the static pressure ratio to the dynamic pressure. In this research, the pressure coefficient Obtained from the relationship $\mathrm{C}_{\mathrm{P}}=\mathrm{P}-\mathrm{P}_{\mathrm{o}} / 0.5 \rho \mathrm{U}^{2}$ where in, $\mathrm{P}$ is the Static pressure of the floor at the desired point, $\mathrm{P}_{\mathrm{o}}$ is the Static pressure at the reference point located at the upstream of ramp, $\rho$ is the water density and $U$ is the average flow velocity. Figure 9 shows the variation of the pressure coefficient in the duct floor relative to the distance from the downstream of ramp. The correlation coefficient between numerical and experimental results for pressure coefficient of the ramp B $\left(\mathrm{t}_{\mathrm{r}} / \mathrm{d}=0.1, \theta=10^{\circ}\right)$ and forced relative air discharges $(\beta=2 \%, 4 \%, 6 \%, 8 \%)$ is in the range of $0.7163<\mathrm{R}^{2}<0.9167$ which emphasizes the accuracy of the numerical model in simulating the flow field.

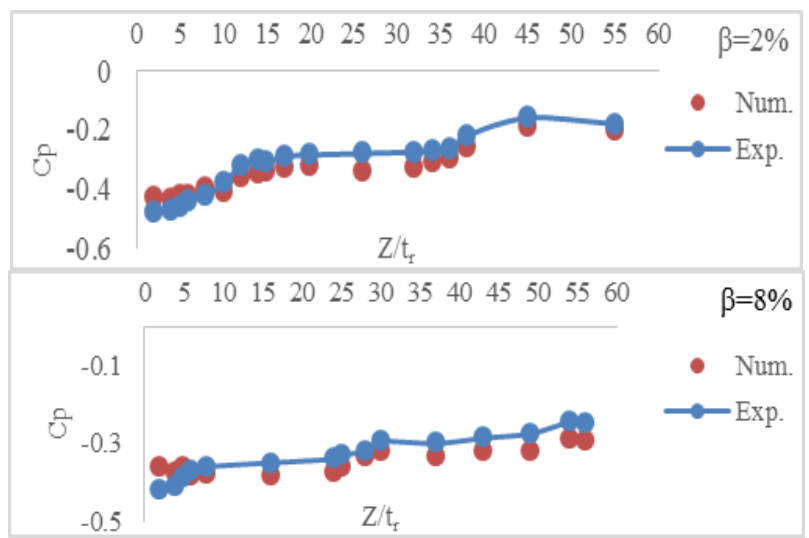

Figure 9. Changes in the pressure coefficient in the duct floor relative to the distance from the end of the ramp $\mathrm{A}\left(\mathrm{t}_{\mathrm{r}} / \mathrm{d}=0.1\right.$, $\left.\theta=5^{\circ}\right)$ and $(\beta=2 \%, 8 \%)$

\subsection{The Effect of Aeration on Flow Characteristics (Cavity Length)}

Variation of forced relative air discharges coefficient $(\beta)$ (which is defined as the air discharge to water discharge) on the cavity length immediately downstream of the aerator ramp is shown in Figure 10. As the results suggest, like the results of Buscher et. al with increasing of forced relative air discharges coefficient $(\beta)$, the cavity length increased and vice versa. In all graphs, the slope of variation trend of the relative air discharges coefficient to the cavity length is altered in location of $\beta=2 \%$ for ramps $A$, $\mathrm{B}\left(\mathrm{t}_{\mathrm{r}} / \mathrm{d}=0.1\right)$ and in location of $\beta=4 \%$ for $\mathrm{ramp} \mathrm{D}\left(\mathrm{t}_{\mathrm{r}} / \mathrm{d}=0.2\right)$, so that before these locations, the change trend between relative air discharges coefficient and cavity lengths has gentle slope, and after these locations, has steep slope. In other words, in high aeration percentages $(\beta)$, the cavity length parameter does not change much.

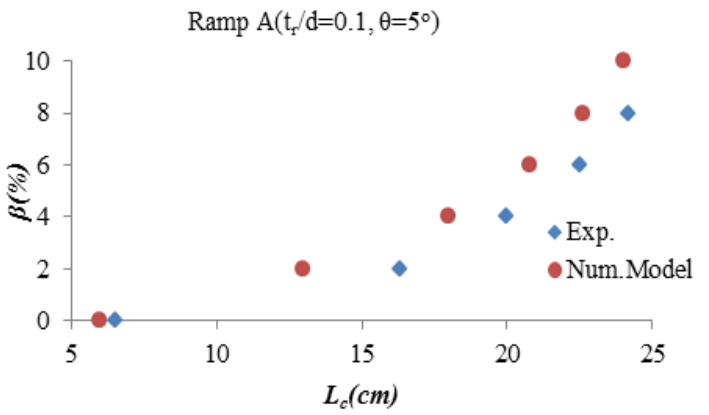



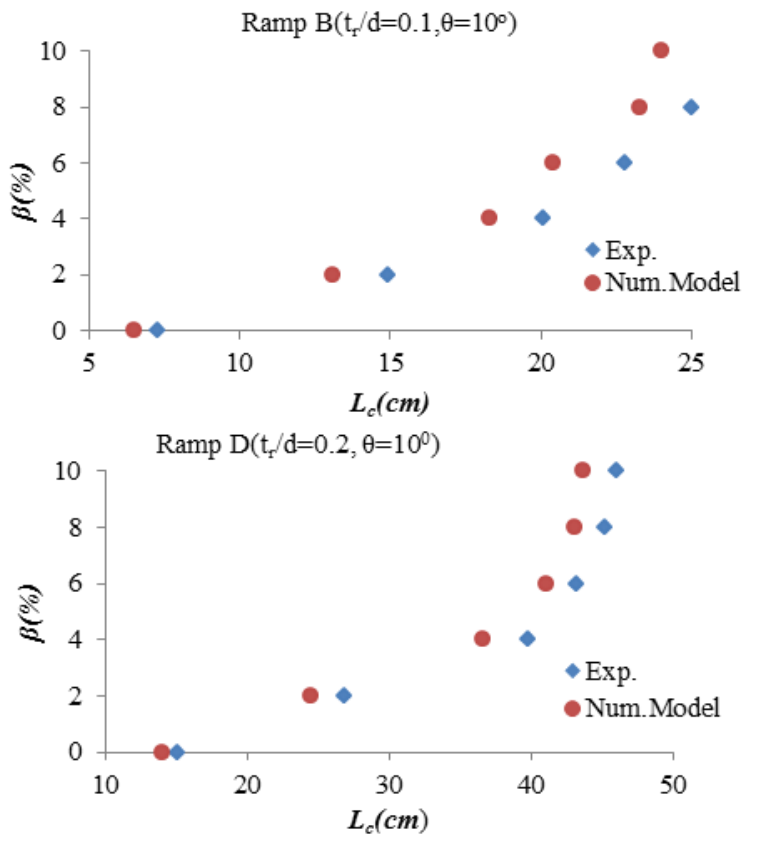

Figure 10. Relative air discharges coefficient variation relative to cavity length for different ramps

In Figure 11 variations in the relative air discharges coefficient of flow are presented as a function of cavity length for different ramps. As you can see, the changes in this function are very close in both quantitative and qualitative terms for ramps of the same height. In other words, the effect of the ramp angle on the aeration coefficient through the relative cavity length is very low (comparing ramp A with $\mathrm{B}$ and $\mathrm{C}$ with $\mathrm{D}$ ). While the effect of ramp height on this relationship is high (ramp A comparison with $\mathrm{C}$ and $\mathrm{B}$ with $\mathrm{D}$ ).

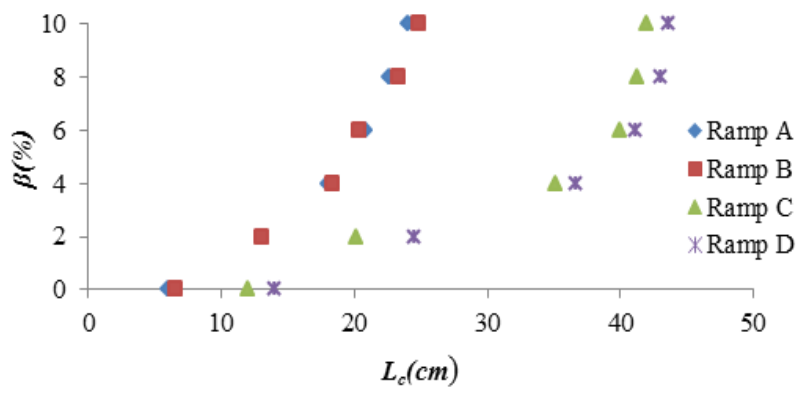

Figure 11. Relative air discharges coefficient variation relative to cavity length for different ramps

By Injection the air below the ramps and forming a cavity, the subpressure decrease immediately below the ramp and the amount of shear stress on the walls decreased and as a result, the velocity of the jet increased. As long as the cavity pressure reaches the atmospheric pressure and after this, the relative cavity length does not change and any extra Injection of air into the cavity from the cavity upper surface, which is now geometrically fixed, goes out and enters the main flow.

\subsection{Determine the Effectiveness range of the forced relative air discharge coefficient $(\beta)$ on relative cavity length $\left(\mathrm{Lc} / \mathbf{t r}_{\mathrm{r}}\right)$}

In order to determine the Effectiveness range of relative air discharge coefficient $(\beta)$ on relative cavity lengths $\left(\mathrm{L}_{\mathrm{c}} / \mathrm{t}_{\mathrm{r}}\right)$, the range of relative air discharge $0 \%<\beta<16 \%$ was investigated that the results are presented in Fig. 12. According to these figures, in the low relative air discharge percentage, the increase in the relative cavity length was more intense and for relative air discharge more than $10 \%$, the relative cavity length does not change more. In other words, the relative cavity length for air percentages of more than $10 \%$ cannot be an effective factor in increasing of the flow aeration.
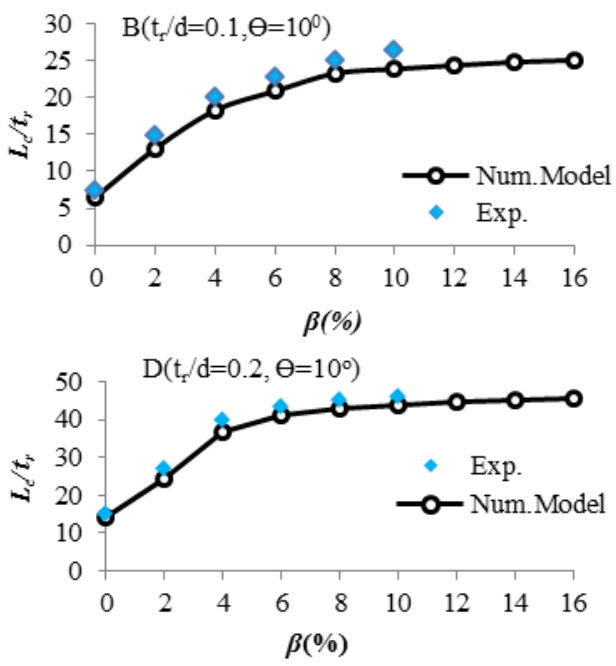

Figure 12. Relative cavity length variation for different relative air discharge rates for ramps $\mathrm{B}$ and $\mathrm{D}$

\section{CONCLUSION}

The result of the study on the flow field near the aerator ramp of the under pressure tunnel with OpenFOAM open source software can be summarized as follows:

1) The correlation coefficient between the results obtained from the numerical model and experimental results for relative cavity length and relative air discharge of $2 \%, 4 \%, 6 \%$ and $8 \%$, are $0.9722,0.9371,0.946$ and 0.966 respectively that indicates the proper agreement between numerical and experimental results as well as the superiority of the TwoPhaseEulerFoam solver of OpenFOAM software in the simulation of two phase flow.

2) The results of the research indicate that in the ramp with different $\left(t_{r} / d\right)$ ratios, with increasing of forced relative air discharge coefficient, the cavity length increased, however this amount in the ramp with different ramp angle $(\theta)$ is minor, therefore in the aeration of flow with aerator ramp, height of ramp has more influence relative to ramp angle.

3) The main effectiveness range of the aeration coefficient on the cavity length was limited to air percent less than $10 \%$, so that for the lower air percent, the effect intensity on the cavity length is much higher than air percent more than $10 \%$. 


\section{References:}

Attari, J., and Zarrati, A.R., 1997. The effect of nappe impact angle on aerator performance. 27th IAHR Congress, San Francisco, USA.

Bhosekar, V. V., Jothiprakash, V. Y., and Deolaikar, P. B., 2012. Orifice Spillway Aerator: Hydraulic Design, Journal of Hydraulic Engineering, 138(6), 563-572

Chanson, H., 1989. Flow downstream of an aerator. Aerator spacing. Journal of Hydraulic Research, IAHR, Vol. 27, No. 4, pp. 519-536.

Chanson, H., 1991. Aeration of a free jet above a spillway. Journal of Hydraulic Research, IAHR, Vol. 29, No. 5, pp. 665667 \& Vol. 29, No. 6, p. 864.

Chanson, H., 1994. Aeration and deaeration at bottom aeration devices on spillway. Canadian Journal of Civil Engineering. 21, pp. 404-409.

Ervine, D.A., and Khan, A.R., 1991. Turbulence measurements in an air-slot ramp aerator. 24th Congress of IAHR, Madrid, Spain, Vol. C, pp.73-79.

Ervine, D.A., Falvey, H.T. and Khan, A.R., 1995. Turbulence flow structure and air uptake at aerators. International Journal on Hydropower \& Dams, Vol. 2, Issue 5, pp. 90-95.

Falvey, H.T., 1990. Cavitation in chutes and spillways. USBR Engineering Monograph, No. 42, Denver, Colorado, USA, 160 pages.

Glazov, A.T., 1984. Calculation of the air-capturing ability of flow behind an aerator Ledge. Gidrotekhnicheskoe Stroitel'stvo, No. 11, Nov., pp. 37-39 (Hydro technical Construction, 1985, Plenum Publ., pp. 554-558).

Kenn, M. J. and Garrod, A. D., 1981. Cavitation Damage and Tarbela Tunnel collapse of 1974. Proc ICE, Part 1, Vol 70, February, pp 65-89.

Kavianpour, M., Toloui, A., and al-Mu'zsoumi, A.S., 2002. Evaluation of pressure fluctuations in downstream of aerator in lower tunnels of dams with circular sections. National Conference on National Hydroelectric Power Plants, June 6 and 7 , Tehran.

May, R.W.P, Brown, P.M. and Willoughby, I.R., 1991. Physical and numerical modeling of aerators for dam spillways. Hydraulics Research Report, No. SR 278, Wallingford, U.K.
Manafpour, M., 2004. Effects of Air Injection on the Flow Immediately Downstream of Deflectors on Spillways. Ph.D. Thesis, UMIST, Manchester University, UK.

Narayanan, R., Manafpour, M. and Kavianpour, R., 2000. Wall pressure Field in the reattaching flow past deflectors, part 2: with air injection. Journal of water \& maritime Engineering, 48 issue, p.39-45.

Peterka, A.J., 1953. The effect of entrained air on cavitation pitting. Joint Meeting Paper, IAHR/ASCE, Minneapolis, Minnesota, Aug., pp. 507-518.

Pinto, N.L., and de S., 1991. Prototype aerator measurements. IAHR Hydraulic Structures Design Manual No. 4, Ed. I.R.

Wood, I.R., 1991. Air entrainment in free-surface flows. IAHR Hydraulic Structures Design Manual No.4, Hydraulic Design Considerations, Balkema publ., Rotterdam, The Netherlands, 149 pages.

Weller, H. G., Jasak, H., and Fureby, C., 1998. A tensorial approach to computational continuum mechanics using objectoriented techniques. Journal of Computational Physics, 12 (6), pp. 620-631.

Wu, J., Ma, F., and Dai, H.C., 2011. Influence of Filling Water on Air Concentration, Journal of Hydrodynamics, 23(5), 601606.

Zarrati, A.R. and Hardwick, J.D., 1995. Mathematical modeling of deaeration zone downstream of aerators. 26th Congress of IAHR, London, U.K., Vol. 2, pp. 220-225.

Zhang, JM, Chen JG, Xu WL., 2011. Three-dimensional numerical simulation of aerated flows downstream sudden fall aerator expansion in a tunnel. Journal of Hydrodynamics. 23(1): 71-80.

Deng, J., Xu, W. L., Lei, J., and Diao, M. J., 2005. Numerical simulation of hydraulic characteristics of high head spillway tunnel, Chinese Journal of Hydraulic Engineering, 36(10), 1209-1212. (in Chinese).

Jothiprakash, V. Y., Bhosekar, V. V., and Deolaikar, P. B., 2015. Flow characteristics of orifice spillway aerator: Numerical model studies," ISH Journal of Hydraulic Engineering, 21(2), 216-230.

Kökpınar, M. A., and Göğüş, M., 2002. High-speed jet flows over spillway aerators, Canadian Journal of Civil Engineering, 29(6), 885-898. doi: 10.1139/102-088, 2002.

Liu, T., and Yang, J., 2014. Three-dimensional computations of water-air flow in a bottom spillway during gate opening, Engineering Applications of Computational Fluid Mechanics, 8(1), 104-115. 
Rahimzadeh,H., Maghsoodi, R., Sarkardeh, H., and Tavakkol, S., 2012. Simulating flow over circular spillways by using different turbulence models, Engineering Applications of Computational Fluid Mechanics, 6(1), 100-109, 2012.

Aydin, M. C. and Ozturk, M., 2009. Verification and validation of a computational fluid dynamics (CFD) model for air entrainment at spillway aerators, Canadian Journal of Civil Engineering, 36(5), 826-836. doi: 10.1139/L09-017.

Zhang, J. M., Chen, J. G., and Xu, W. L., 2011. Threedimensional numerical simulation of aerated flows downstream sudden fall aerator expansion-in a tunnel, Journal of Hydrodynamics, Ser. B, 23(1), 71-80. doi: 10.1016/S10016058(10)60090, 2011.

Zhang, X. D., 2004. Three dimensional numerical simulation of high velocity flow in spillway tunnels, [Ph.D. thesis], China Institute of Water Resources and Hydropower, Beijing, China.

Zhang, H. W., Liu, Z. P., Zhang, D., and Wu,Y. H., 2008. Numerical simulation of aerated high velocity flow downstream of an aerator, Journal of Hydraulic Engineering, vol. 39, no. 12, pp. 1302-1308, 2008. 